\title{
Dysplasia epiphysealis hemimelica of the radial head: a rare case report
}

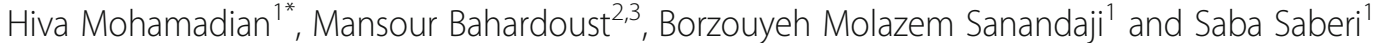

\begin{abstract}
Background: Dysplasia epiphysealis hemimelica (DEH) is a rare benign overgrowth generally affecting the epiphyses and short bones of the lower limbs. DEH in the elbow joint is extremely rare, and to date, only three cases of DEH have been reported in the radial head.

Case presentation: In this study, we report a case of DEH located in the radial head of the right elbow of a 10year-old boy, which was presented with elbow pain and limited range of motion. In clinical examination, an asymmetrical enlargement was observed over the elbow. The lesion was resected surgically, and the patient's symptoms resolved afterward. The histologic analysis of the lesion confirmed the diagnosis of DEH.
\end{abstract}

Conclusion: This report highlights the role of DEH in the differential diagnosis of elbow pathologies, particularly its differentiation from osteochondroma.

Keywords: Dysplasia epiphysealis hemimelica, Trevor's disease, Radial head, Elbow

\section{Background}

Dysplasia epiphysealis hemimelica (DEH), also known as Trevor's disease, is a nonhereditary developmental disorder with unknown etiology consisting of a benign intra-articular mass confined by epiphysis of long bones $[1,2]$. It is an osteocartilaginous lesion resulting from an abnormal proliferation of cartilage tissue, which generally involves one-half of the epiphysis, therefore termed 'hemimelic' [2]. DEH is an extremely rare condition that mainly affects children aged $2-15$ years, with an incidence of 1 in 1,000,000 individuals [1,3]. Although the histological findings of DEH are similar to osteochondroma, its clinical, radiological, histological, and molecular characteristics favor a different entity [4]. However, differentiation of DEH with chondroblastoma [5] and parosteal osteosarcoma could be challenging, particularly in the early stages [6].

\footnotetext{
* Correspondence: garza.1390@yahoo.com

${ }^{1}$ Rasoul-e-Akram Hospital, Iran University of Medical Sciences, Tehran, Iran

Full list of author information is available at the end of the article
}

DEH mostly occur in the lower limb, and upper limb involvement is very rare. The carpal bones and the wrist are the most frequent upper-extremity involvement of DEH [7]. To the best of our knowledge, only a few numbers of DEH have been reported around the elbow [8]. In this study, we report a case of DEH located in the radial head of a 10-year-old boy, which was presented with pain and limited elbow range of motion.

The patient's parents provided written informed consent to use the data attributed to this case for publication.

\section{Case presentation}

A 10-year-old boy was referred to our center with a painful right elbow. The patient and his family had no considerable medical history. The patient had no history of elbow trauma and surgery, as well. In clinical examination, an asymmetric enlargement was noticed on the right elbow. In physical examination, the elbow range of motion was restricted so that a flexion-extension motion $\operatorname{arc}$ of $30-90^{\circ}$ and $15^{\circ}$ of pronation to $20^{\circ}$ of supination was recorded.

(c) The Author(s). 2021 Open Access This article is licensed under a Creative Commons Attribution 4.0 International License, which permits use, sharing, adaptation, distribution and reproduction in any medium or format, as long as you give appropriate credit to the original author(s) and the source, provide a link to the Creative Commons licence, and indicate if changes were made. The images or other third party material in this article are included in the article's Creative Commons licence, unless indicated otherwise in a credit line to the material. If material is not included in the article's Creative Commons licence and your intended use is not permitted by statutory regulation or exceeds the permitted use, you will need to obtain permission directly from the copyright holder. To view a copy of this licence, visit http://creativecommons.org/licenses/by/4.0/ The Creative Commons Public Domain Dedication waiver (http://creativecommons.org/publicdomain/zero/1.0/) applies to the data made available in this article, unless otherwise stated in a credit line to the data. 

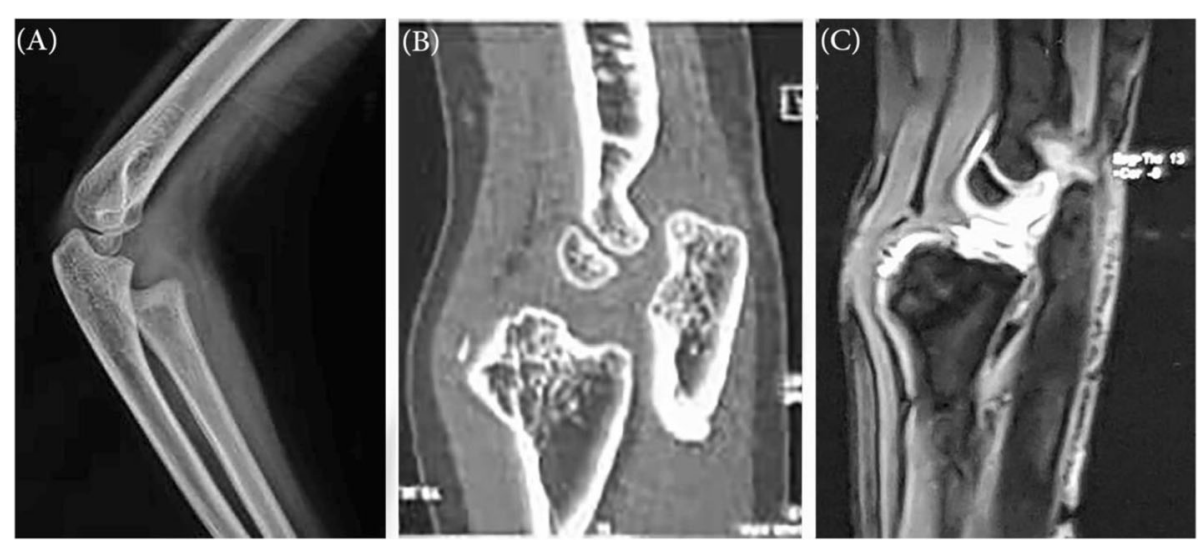

Fig. 1 a Plain radiograph and $\mathbf{b} C T$ scan of the elbow showing irregular mass with focal ossification at the epiphyseal section of the proximal radius; c MRI of the elbow showing an epiphyseal osteocartilaginous lesion originating in the radial head epiphysis, Fig. 2: The histologic of the excised lesion revealed clusters of chondrocyte arranged in a fibrillary matrix, a thick cartilaginous cap, and ossification centers

The findings on the plain radiograph (Fig. 1a) and computed tomography (CT) scan (Fig. 1b) revealed an irregular mass with focal ossification at the epiphyseal section of the proximal radius. Magnetic resonance imaging (MRI) demonstrated an epiphyseal osteocartilaginous lesion originating in the radial head epiphysis (Fig. 1c). The annular ligament could not be seen clearly in preoperative MRI. With suspecting a diagnosis of $\mathrm{DEH}$, the decision was made for resecting the lesion surgically. Under general anesthesia, in a supine position, and through the anterior-lateral approach to the radial head, the lesion was resected and sent to the pathology department for further evaluation. The remnant of the annular ligament was seen intraoperatively and resected.

The histologic evaluation of the excised lesion revealed clusters of chondrocyte arranged in a fibrillary matrix, a thick cartilaginous cap, and ossification centers, which were consistent with the diagnosis of DEH (Fig. 2).
The patient's arm was supported in a swathe and sling for 2 weeks. The full range of motion exercises and physical therapy was administered two times a week. The first visit to the patient was 2 weeks after the surgery. The patient had no pain, and the elbow range of motion was near to normal (flexion-extension: 0-130', pronation: $50^{\circ}$, supination: $\left.50^{\circ}\right)$. At the six-month follow-up, the patient was still pain-free and had a full range of elbow movements. No sign of recurrence was noticed in the follow-up radiographs. Secondary ossification or growth arrest of the forearm bones was not seen either (Fig. 3).

\section{Discussion and conclusion}

In this study, we reported a case of DEH presented in the right elbow of a 10-year-old boy, which was associated with pain and limited elbow range of motion. The definitive diagnosis of $\mathrm{DEH}$ was made based on the

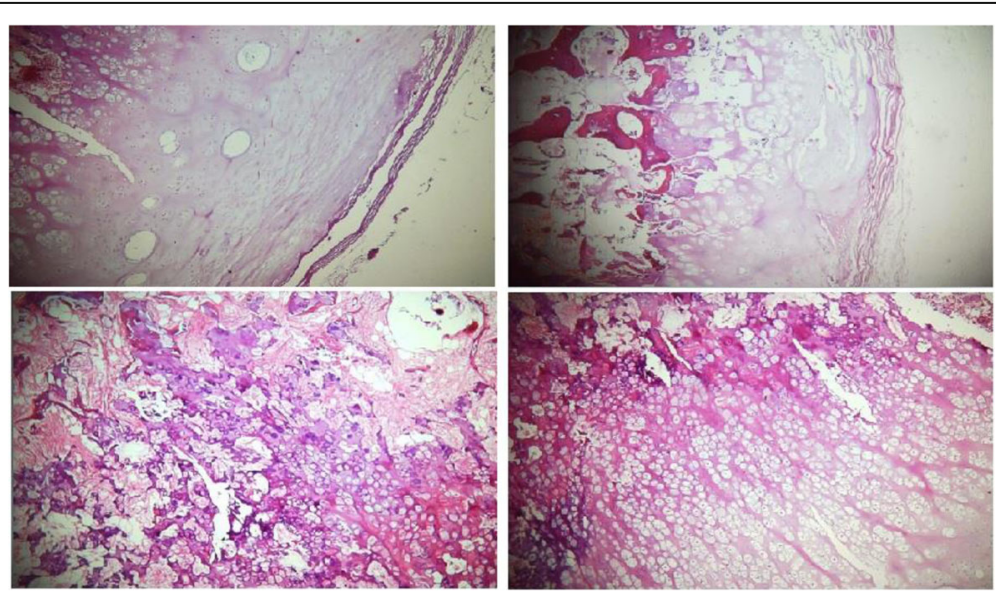

Fig. 2 Histologic analysis of the lesion showing clusters of chondrocyte arranged in a fibrillary matrix, a thick cartilaginous cap, and ossification centers 


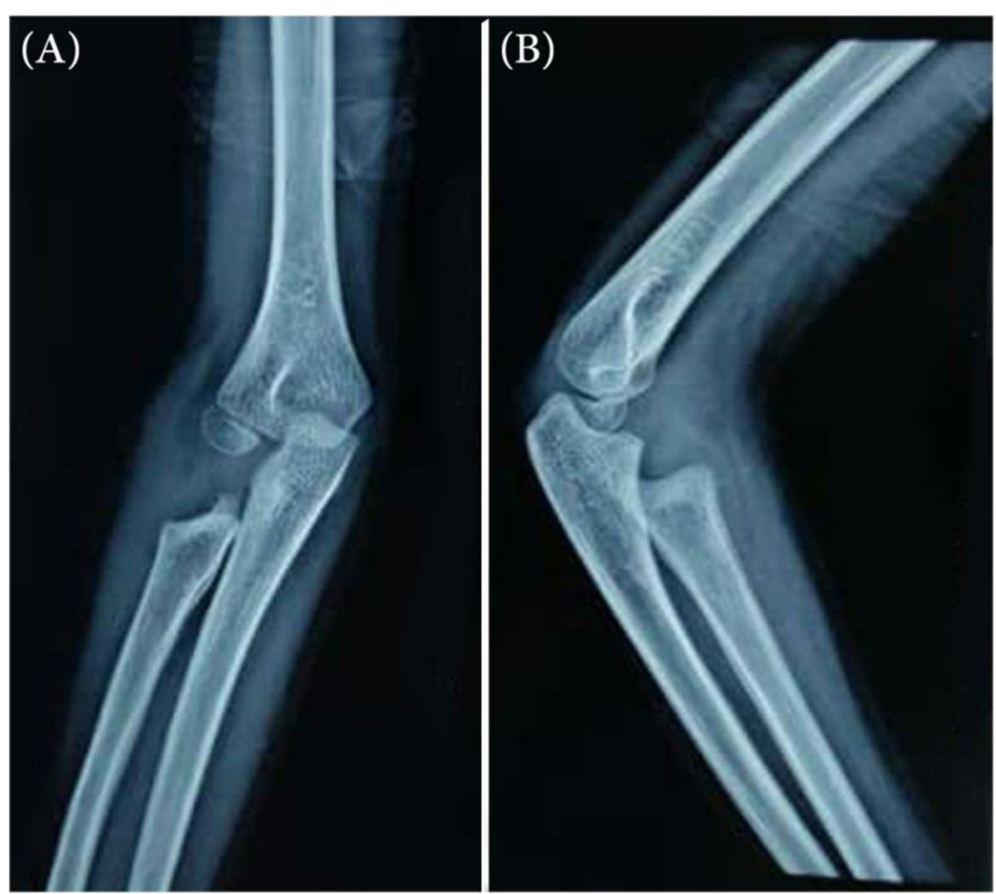

Fig. 3 a Anteroposterior and $\mathbf{b}$ lateral radiograph of the elbow 1 year after the surgery showing no sign of secondary ossification or growth arrest of the forearm bone

histologic analysis of the excised specimen. The patient remained symptom-free after the resection, and no sign of recurrent was seen in the follow-up radiographs.

$\mathrm{DEH}$ of the upper extremity is rare. Nearly 39 cases of upper-extremity DEH have been reported in earlier literature from which DEH of the elbow is reported in 8 cases. Radial head involvement has been reported in 3 out of these 7 cases [9].

Kircher et al. reported a case of DEH in a 17-year-old boy who was admitted with the diagnosis of a recurrent cartilaginous exostosis at the radial head 4 years after initial excision. The patient was presented with elbow tenderness and limited range of motion. On the clinical examination, a progressive enlargement was noticed at the left elbow. The lesion was resected surgically, and the histological analysis of the extracted specimen confirmed the diagnosis of DEH. At the final follow-up, 16 months after the surgery, the patient was pain-free function and had no limitation in the elbow range of motion. Moreover, no sign of recurrence was presented on the follow-up radiographs [9]. The presentation and outcome of DEH in our case were very similar to the case of Kircher et al. The DEH of the elbow has also been reported in two other investigations $[3,10]$.

Osteochondroma is the most frequent differential diagnosis of $\mathrm{DEH}$, as malignant transformation is seen in $1 \%$ of solitary osteochondromas, but not in DEH [11]. This differentiation can be made using clinical, radiologic, and pathologic parameters. While DEH generally occurs in young children aged 2-15 years and originates in the epiphysis of long bones, osteochondroma most frequently occurs at the age of 10-30 years of age and originates from the metaphysis. Histologically, DEH presents with a thick disorganized cartilage cap, whereas osteochondromas present with organized cartilage resembling the normal growth plate $[4,12]$.

Parosteoal osteosarcoma and DEH can also be sometimes difficult to differentiate, particularly in the early stages and if the talus is affected. In these cases, CT scanning could be very helpful in identifying calcification or ossification within the DEH lesion [13].

The decision for surgical treatment of DEH depends on several factors, such as the symptoms, location, and size of the lesion. Generally, surgical excision is only considered for those patients with pain or functional limitation. Since the malignant transformation of $\mathrm{DEH}$ has not been reported, observation might be enough for asymptomatic cases. However, delayed diagnosis or treatment might result in an enlarged intra-articular mass, making the decision for surgical treatment more difficult. Therefore, early excision is recommended depending on the location of DEH [14]. To avoid unnecessary surgical intervention, a preoperative biopsy could be useful, particularly in the early stages of the disease or when the lesion is presented in unusual locations [15].

Based on our experience, DEH of the radial head could be favorably treated with surgical excision, and the patient's symptoms will completely resolve afterward. The 
present case raises awareness regarding the importance of $\mathrm{DEH}$ in the differential diagnosis of elbow pathologies, particularly with osteochondroma.

\section{Abbreviations}

DEH: Dysplasia Epiphysealis Hemimelica; CT: Computerized Tomographic

\section{Acknowledgements}

Herby, the authors would like to express gratitude to the Vice Chancellor for research of Iran University of Medical Sciences.

\section{Authors' contributions}

Conception and design: S. S, B. M and H. M. Analysis and interpretation of data: M. B. Data collection: M. B, H. M. Authors participate in drafting the article or revising: S. S, B. M, M. B and H.M. All authors have read and approved the manuscript and ensure that this is the case. I attest to the fact that all authors listed on the title page have read and approved the manuscript, attest to the validity and legitimacy of the data and its interpretation, and agree to its submission to "BMC Musculoskeletal Disorders" for an evaluation and reviewing for maybe publishing.

\section{Authors' information}

Saba Saberi (MD, Resident of Radiology, Rasoul-e- Akram Hospital, Iran University of Medical Sciences, Tehran, Iran), Borzouyeh Molazem sanandaji (M.D, Resident of Orthopedic, Rasoul-e-Akram Hospital, Iran University of Medical Sciences, Tehran, Iran), Mansour Bahardoust (Bone and Joint Reconstruction Research Center, Shafa Orthopedic Hospital, Iran University of Medical Sciences, Tehran, Iran), Hiva Mohamdian (Assistant Professor of Orthopedic surgeon, Rasoul-e-Akram Hospital, Iran University of Medical Sciences, Tehran, Iran)

\section{Funding}

We have no funding resource for this study.

\section{Availability of data and materials}

Not applicable.

\section{Ethics approval and consent to participate}

This study was approved by the ethics committee of Iran University of medical science.

\section{Consent for publication}

Written informed consent was obtained from the patients' mother for publication of this case report and any accompanying images.

\section{Competing interests}

The authors declare that they have no competing interests.

\section{Author details}

${ }^{1}$ Rasoul-e-Akram Hospital, Iran University of Medical Sciences, Tehran, Iran ${ }^{2}$ Department of Epidemiology, School of Public Health, Shahid Beheshti University of Medical Sciences, Tehran, Iran. ${ }^{3}$ Bone and Joint Reconstruction Research Center, Shafa Orthopedic Hospital, Iran University of Medical Sciences, Tehran, Iran.

Received: 2 May 2020 Accepted: 20 January 2021

Published online: 05 February 2021

\section{References}

1. Finidori G, Rigault P, Padovani J, Naouri A. Dysplasie épihysaire hémimélique. Revue de chirurgie orthopedique et reparatrice de l'appareil moteur. 1978:64(5):367-74.

2. Moseley J. Dysplasia epiphysealis hemimelica (tarso-epiphyseal aclasis). J Mount Sinai Hospital, New York. 1957;24(4):510.

3. Kettelkamp DB, Campbell CJ, Bonfiglio M. Dysplasia epiphysealis hemimelica: a report of fifteen cases and a review of the literature. JBJS. 1966;48(4):746-66.

4. Glick R, Khaldi L, Ptaszynski K, Steiner GC. Dysplasia epiphysealis hemimelica (Trevor disease): a rare developmental disorder of bone mimicking osteochondroma of long bones. Hum Pathol. 2007;38(8):1265-72.
5. Karkhur Y, Tiwari A, Verma T, Maini L. Unusual presentation of chondroblastoma mimicking Trevor's disease. J Postgrad Med. 2017;63(3): 197-9 PubMed PMID: 28272066. eng.

6. Bahk W-J, Lee H-Y, Kang Y-K, Park J-M, Chun K-A, Chung Y-G. Dysplasia epiphysealis hemimelica: radiographic and magnetic resonance imaging features and clinical outcome of complete and incomplete resection. Skelet Radiol. 2010;39(1):85.

7. Rao SB, Roy DR. Dysplasia epiphysealis hemimelica. Upper limb involvement with associated osteochondroma. Clin Orthop Relat Res. 1994;307:103-9.

8. Maalouf A, El Hage S, Haidar R, Dagher F, Kharrat K, Ghanem I. Dysplasia epiphysealis hemimelica of the elbow. J Pediatr Orthop B. 2011;20(3):142-6.

9. Kircher J, Westhoff B, Bittersohl B, Ziskoven C, Krauspe R. A rare case of Trevor's disease (dysplasia epiphysealis hemimelica) in the elbow. J Shoulder Elb Surg. 2013;22(2):e12-e5.

10. Mouchet A. La tarsomegalie. J Radiol Electrol. 1926;10:289-93.

11. Murphey MD, Choi JJ, Kransdorf MJ, Flemming DJ, Gannon FH. Imaging of osteochondroma: variants and complications with radiologic-pathologic correlation. Radiographics. 2000;20(5):1407-34.

12. Stevens J, Welting TJ, Witlox A, van Rhijn LW, Staal HM. Dysplasia epiphysealis hemimelica: a histological comparative study with osteochondromas. J Child Orthop. 2017;11(3):160-8.

13. Arealis G, Nikolaou VS, Lacon A, Ashwood N, Hayward K, Karagkevrekis C. Trevor's disease: a literature review regarding classification, treatment, and prognosis apropos of a case. Case Rep Orthop. 2014;2014:940360.

14. Luevitoonvechkij S, Khunsree S, Sirirungruangsarn Y, Settakorn J. Dysplasia epiphysealis hemimelica: a huge articular mass with unpredictable surgical results. Case Rep. 2012;2012:bcr2012007259.

15. Gao F, Chen G, Wang R, Huang P, Wang J, Xu W. TKA in the treatment of bilateral dysplasia epiphysealis hemimelica (Trevor's disease) of the knee in a 50-year-old man: a case report. BMC Musculoskelet Disord. 2020;21(1):1-5.

\section{Publisher's Note}

Springer Nature remains neutral with regard to jurisdictional claims in published maps and institutional affiliations.

\section{Ready to submit your research? Choose BMC and benefit from:}

- fast, convenient online submission

- thorough peer review by experienced researchers in your field

- rapid publication on acceptance

- support for research data, including large and complex data types

- gold Open Access which fosters wider collaboration and increased citations

- maximum visibility for your research: over $100 \mathrm{M}$ website views per year

At $\mathrm{BMC}$, research is always in progress.

Learn more biomedcentral.com/submissions 